\title{
Genome-Wide Analyses on Loss of Heterozygosity in Head and Neck Squamous Cell Carcinomas
}

\author{
Levent Bekir Beder, Mehmet Gunduz, Mamoru Ouchida, Kunihiro Fukushima, \\ Esra Gunduz, Sachio Ito, Akiko Sakai, Noriyuki Nagai, Kazunori Nishizaki, and \\ Kenji Shimizu
}

Departments of Otolaryngology (LBB, KF, KN), Oral Pathology and Medicine (MG, EG, NN), and Molecular Genetics (MO, SI, AS, KS), Graduate School of Medicine and Dentistry, Okayama University, Shikata-cho, Okayama, Japan

\begin{abstract}
SUMMARY: Head and neck squamous cell carcinoma (HNSCC) is a frequent malignancy with a poor survival rate. Identifying the tumor suppressor gene (TSG) loci by genomic studies is an important step to uncover the molecular mechanisms involved in HNSCC pathogenesis. We therefore performed comprehensive analyses on loss of heterozygosity (LOH) using a genome-wide panel of 191 microsatellite markers in 22 HNSCC samples. We found 53 markers with significantly high LOH (>30\%) on 21 chromosomal arms; the highest values of those were observed on 3p, 9p, 13q, 15q, and 17p, corresponding to D3S2432 (67\%), D9S921-D9S925 (67\%) and GATA62F03 (86\%), D13S1493 (60\%), D15S211 (62\%), and D17S1353 (88\%), respectively. Fifteen hot spots of LOH were defined in 13 chromosomal arms: 2q22-23, 4p15.2, 4q24-25, 5q31, 8p23, 9p23-24, 9q31.3, 9q34.2, $10 q 21,11 q 21-22.3,14 q 11-13,14 q 22.3,17 p 13,18 q 11$, and $19 q 12$ as loci reported previously in HNSCCs. Furthermore, we identified five novel hot spots of LOH on three chromosomal arms in HNSCC at 2q33 (D2S1384), 2q37 (D2S125), 8q12-13 (D8S1136), 8q24 (D8S1128), and 15q21 (D15S211). In conclusion, our comprehensive allelotype analyses have unveiled and confirmed a total of 20 possible TSG loci that could be involved in the development of HNSCC. These results provide useful clues for identification of putative TSGs involved in HNSCC by fine mapping of the suspected regions and subsequent analysis for functional genes. (Lab Invest 2003, 83:99-105).
\end{abstract}

$H$ ead and neck squamous cell carcinomas (HNSCCs) are a diverse group of cancers and are frequently aggressive in their biologic behavior. They account for $1 \%$ to $2 \%$ of all cancer deaths in both the United States and Japan. Most patients with this malignancy have advanced disease at presentation, with regional disease in $43 \%$ and distant metastases in 10\% (Pfister et al, 1997). The overall survival rate for this disease group remains poor, largely because of the high incidence of recurrent disease at the primary site or in the regional lymph nodes. Patients presenting with HNSCC also demonstrate a high incidence of second primary tumors in the upper aerodigestive tract, which may be synchronous or metachronous.

In neoplastic progression, most of the sporadic solid tumors result from a multistep process of accumulated genetic and epigenetic alterations (Renan, 1993). Among these changes, inactivation of the tumor suppressor genes (TSGs) is one of the most critical steps. In this process, the deletion of targeted

\section{DOI: 10.1097/01.LAB.0000047489.26246.E1}

Received September 27, 2002.

This work was supported by grant-in-aids from the Ministry of Education, Science, Sports and Culture of Japan (to KS).

Address reprint requests to: Dr. Kenji Shimizu, Department of Molecular Genetics, Graduate School of Medicine and Dentistry, Okayama University, Shikata-cho 2-5-1, Okayama 700-8558, Japan. E-mail: shimke47@md.okayama-u.ac.jp chromosomal regions eliminates the one allele, while inactivating events (mutation, deletion, or promoter hypermethylation) affect the other allele of the concerning TSG (Knudson, 1971). The detection of frequent loss of heterozygosity (LOH) in a chromosomal locus is considered to be critical evidence for the localization of a TSG. Large-scale genomic studies identified the chromosomal locations of several different human TSGs. A substantial number of TSGs involved in the genesis of several cancer types, including HNSCCs, have already been discovered. On the basis of such studies, the p53, p16, ING1, and ING3 genes have been reported as TSGs involved in HNSCCs (Gunduz et al, 2000, 2002; Reed et al, 1996; Somers et al, 1992). However, a variety of large scale genome analysis techniques suggested that a number of such genes remain to be unveiled.

Previously three different genome-wide allelotype analyses (Ah-See et al, 1994; Field et al, 1995; Nawroz et al, 1994) of HNSCC using 50, 58, and 145 microsatellite markers, respectively, revealed frequent $\mathrm{LOH}$ at several chromosomal regions including $3 p, 4 q, 5 q, 6 p, 8 p, 8 q, 9 q, 11 q, 13 q, 14 q, 17 p$, $18 q$, and $19 q$. However, our study is the most comprehensive genomic study of HNSCCs to date, covering all of the nonacrocentric chromosome arms with 191 microsatellite markers, most of which are different from those used previously. In the present study, we aimed to determine frequently 
deleted chromosomal locations and ultimately to reveal new putative TSGs in HNSCCs.

\section{Results}

\section{LOH Frequency of Each Chromosomal Arm}

DNA from matched pairs of tumor and normal tissues of 22 patients were analyzed comprehensively for LOH by using 223 highly polymorphic microsatellite markers. PCR was successfully performed for 191 (85\%) of 223 markers with about $70 \%$ of informative allelotypes. By using these markers, the frequency of $\mathrm{LOH}$ (number of cases with $\mathrm{LOH} /$ number of informative cases) ranged from $0 \%$ to $88 \%(23 \pm 17 \%$; mean $\pm \mathrm{SD})$. Representative profiles of microsatellite analysis with $\mathrm{LOH}$ are shown in Figure 1. $\mathrm{LOH}$ frequencies for each chromosomal arm, calculated by dividing the total number of cases with LOH by the total number of informative cases on the same arm level, varied between $0 \%$ (16p) and 73\% (9p) (21 $\pm 15 \%$; mean \pm SD). Chromosomal arms 3p, 9p, 13q, 15q, and 17p showed $\mathrm{LOH}$ frequencies of higher than $40 \%$, whereas the $\mathrm{LOH}$ frequencies of $2 \mathrm{q}, 3 \mathrm{q}, 4 \mathrm{p}, 4 \mathrm{q}, 5 \mathrm{q}, 8 \mathrm{p}, 8 \mathrm{q}, 9 \mathrm{q}, 10 \mathrm{q}$, $11 p, 11 q$ and $14 q$ were more than $20 \%$. Furthermore, $3 p$ and $15 q$ seemed to have total deletion of each chromosomal arm in four and five tumor samples, respectively, which made it difficult to focus on the target area carrying putative TSG. On the other hand, $\mathrm{LOH}$ was not detected on 16p arm (Fig. 2). All the markers explored on sex chromosomes showed almost no informative results; consequently, those could not be evaluated.

\section{LOH at Specific Loci}

When evaluating the significance of the markers, $\mathrm{LOH}$ frequency of more than $30 \%$ of the informative cases (which represents losses presumably associated with the cancer-specific phenotype; Girard et al, 2000) was considered to be significant for the presence of putative TSGs. Among 191 primers, we found 53 markers with significantly high $\mathrm{LOH}$ on 21 chromosomal arms. The highest values were seen with D13S1493 (60\%), D15S211 (62\%), D3S2432 (67\%), D9S921 (66\%), D9S925 (66\%), GATA62F03 (86\%), D17S1298 (75\%), and D17S1353 (88\%). All the markers located on the $3 p, 9 p, 13 q$, and 17p arms showed LOH frequency higher than $40 \%$. On the other hand, we could not found any significant marker on several chromosomal arms including 1p, 1q, 2p, 3q, 5p, 6p, 7p, 7q, 10p, 12 p, 12q, 16p, 16q, 18p, 19p, 20p, 20q, 21q, and 22q.

\section{Hot Spots of $\mathrm{LOH}$}

We defined the hot spot loci for markers with frequent $\mathrm{LOH}$ but that retained heterozygosity for the flanking microsatellites. According to this definition, 19 hot regions were found on 13 chromosomal arms: 2q33 (D2S1384), 2q22-23 (D2S1334-D2S1399), 2q37 (D2S125), 4p15.2 (D4S2639), 4q24-25 (D4S2623), 5q31.3 (D5S1480), 8p23.2 (D8S264), 8q13.1 (D8S1136), 8q24 (D8S1128), 9p23-24 (D9S925, GATA62F03), 9q31.3 (D9S930), 9q34.2 (D9S158), 10q21 (D10S1221), 11q21-22.3 (D11S2000, D11S2002), 14q11-13 (D14S608-D14S306), 14q22.3 (D14S592), 17p13 (D17S1353), 18q11 (D18S877), and 19q12 (D19S433). Results of LOH analysis on these markers are shown in Figure 3. Among these areas, 2q22-23, 2q37, 8q13, and 8q24 were identified as new hot loci in HNSCCs. With respect to the $15 \mathrm{q}$ arm, we found a significantly high frequency of $\mathrm{LOH}$ at D15S211 (62\%), although the entire 15q arm seemed to be lost in approximately $25 \%$ of HNSCC specimens.

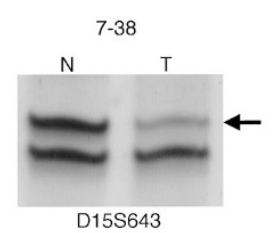

20-16

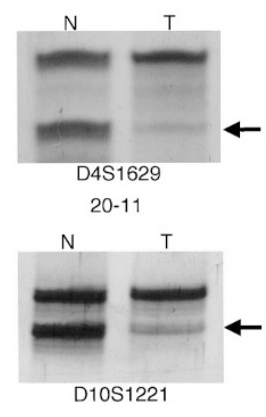

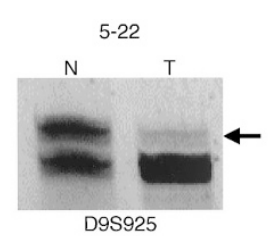

8-26

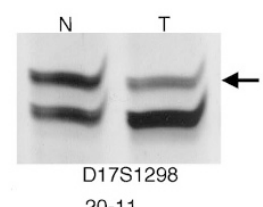

20-11

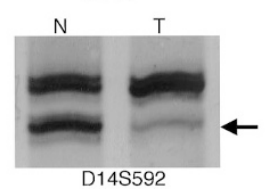

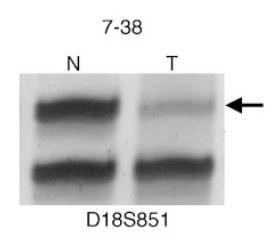

7-31
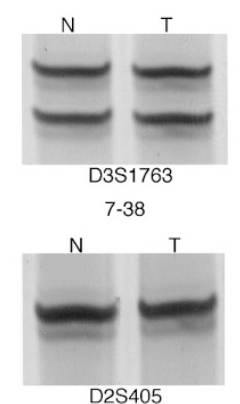

Figure 1.

Representative results of microsatellite analysis for loss of heterozygosity (LOH) by using highly polymorphic microsatellite markers at several chromosomal regions in the samples of head and neck squamous cell carcinomas (HNSCCs). DNA of tumor ( $T$ ) and corresponding normal $(M)$ tissues are shown with microsatellite markers indicated at the bottom and sample numbers on the top. Lost alleles in samples with LOH are depicted by arrows. Samples 7-31 (D3S1763) and 7-38 (D2S405) represent cases for retention of heterozygosity and noninformative, respectively. 


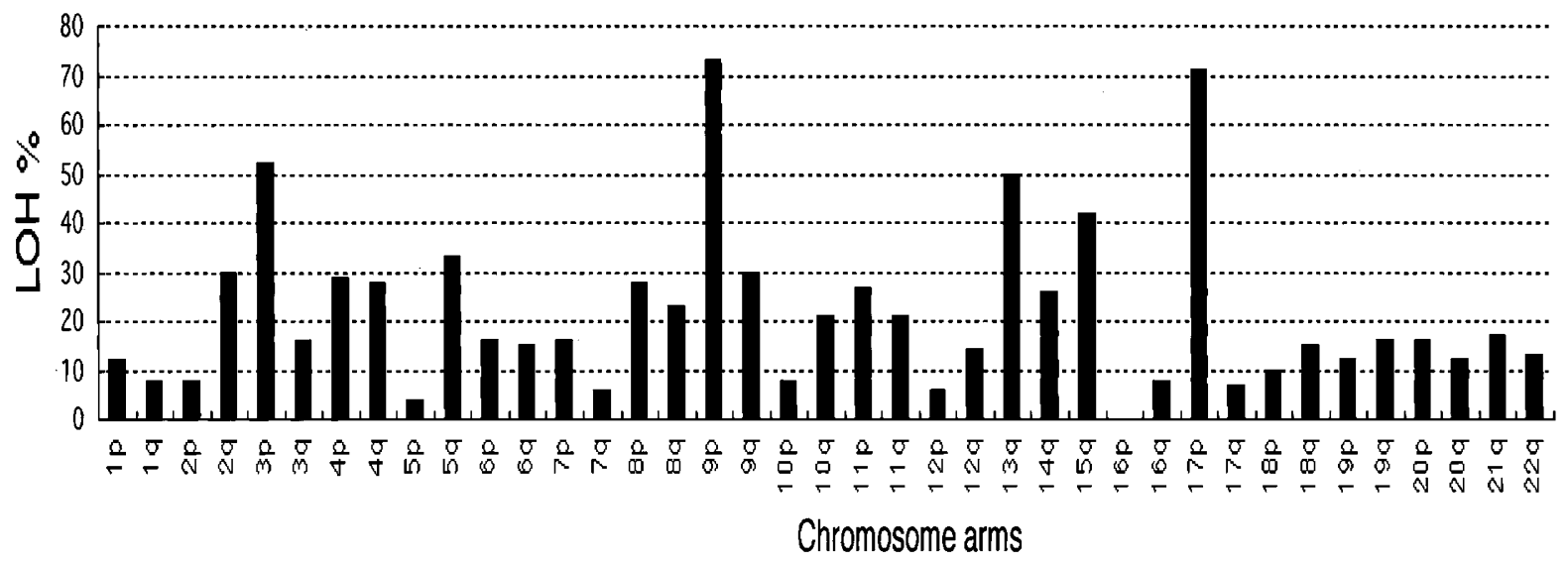

Figure 2.

Frequency of LOH at each chromosome arm in 22 cases of HNSCC. LOH frequencies were calculated by total number of markers with LOH divided by total number of informative markers on the same arm level.

\section{Discussion}

We found frequent allelic losses (more than 30\%) in 53 different loci on 21 chromosomal arms by comprehensive microsatellite allelotype analysis in HNSCCs. Detection of hot spots is critical for defining the possible TSGs. In this regard, 4 to 5 of the 20 hot spot loci we found seemed to be new candidate TSG regions responsible for HNSCC development.
Chromosome $3 p$ and $15 q$ arms were likely to be completely deleted in 5 and 4 of the 20 tumor samples, respectively. Although this does not specify the location regarding the putative TSG, it implies the existence of new TSGs in these chromosomal regions, which remain to be clarified by further analysis.

On chromosome 2q, three different hot spots were defined: D2S1384 (2q33.1), D2S125 (2q37), and
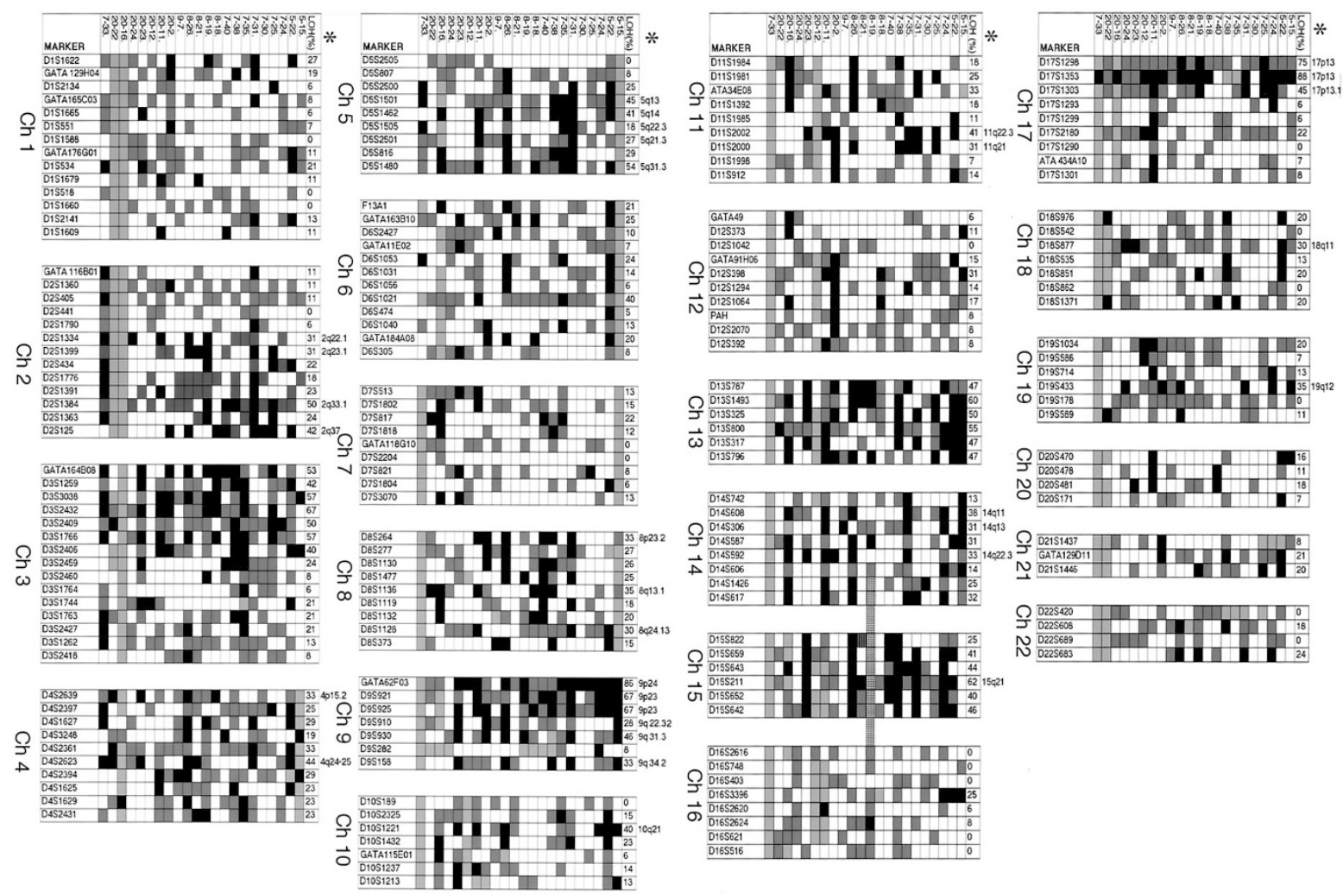

Figure 3.

Complete allelotyping results of 22 HNSCC samples. Microsatellite markers are shown on the left and sample numbers on the top of the tables. The percentages of $\mathrm{LOH}$ at each location are displayed on the right of each panel. Hot spots are depicted by cytogenetic map position on the far right of each panel. Among these areas, 2q22-23, 2q37, 8q13, 8q24, and 15q21 were identified as novel hot loci for LOH in HNSCCs. Filled box, LOH; open box, retention of heterozygosity; gray box, noninformative; hatched box, not done; Ch, chromosome. ${ }^{*}$ Cytogenetic location of hot spots. 
D2S1334-D2S1399 (2q22.1-2q23.1), locations with $\mathrm{LOH}$ frequencies of $50 \%, 42 \%$, and $31 \%$, respectively. In HNSCC, only a few studies were reported in the literature regarding significantly deleted regions on chromosome 2 . The only study using microsatellite analysis found a $32 \%$ loss in 2q32 (Ransom et al, 1998). Other studies using comparative genomic hybridization denoted losses in 2q35-37 (43\%) (Bockmuhl et al, 1996) and 2q33 (29\%) (Weber et al, 1998) in oral malignancies. On the 2 q33 band, frequent $\mathrm{LOH}$ was also revealed in various human tumors, including neuroblastoma and lung cancer. In this locus, the caspase 8 gene for neuroblastoma (Takita et al, 2001), TPEF for various tumor cell lines, and the PLC- $L$ gene for small cell lung carcinoma (Kohno et al, 1995) were suggested as TSGs. Inhibition of caspase 8 in a HNSCC cell line, KB, resulted in the reduction of the apoptotic cell fraction and changes in expression of Fas-related genes after irradiation (Uno et al, 2002). This study and our data that showed frequent deletion in the 2 q33 region suggest the caspase 8 gene as a candidate TSG in HNSCCs. The regions at 2q22-23 and 2 q37 are new hot loci for HNSCCs, although frequent $\mathrm{LOH}$ in breast carcinoma at the 2q22 (41\%) region and in lung and esophageal carcinomas at the 2q37 locus were shown (Hu et al, 2000; Otsuka et al, 1996).

Fractional or complete allelic loss of $3 p$ is predicted as an early and basic event in HNSCC development (Bockmuhl et al, 1996). We found frequent LOH at the $3 p$ region, with an average deletion ratio of $52 \%$. At least five tumors (25\%) revealed loss at all informative markers, suggesting complete deletion of $3 p$. Our findings on $3 p$ are consistent with those of previous studies. Based on discrete regions of deletion on the $3 p$ arm in a variety of human cancers, several candidate TSGs were suggested, including VHL, FHIT, RASSF1, and H37 (Dammann et al, 2000; Kisielewski et al, 1998; Latif et al, 1993; Oh et al, 2002).

Deletions on chromosome 4 were suggested to have appeared in the late stages of HNSCC (Califano et al, 1996). Our study defined two different loci with significant LOH. The more prominent locus, 4q24-25 (D4S2623), overlaps with some previous reports on HNSCCs (Pershouse et al, 1997; Wang et al, 1999). The other discrete locus, $4 \mathrm{p} 15$, is involved in a more extensive band (4p14-pter) in HNSCC (Bockmuhl et al, 1996). On the other hand, the same region was found to be significantly deleted in breast carcinoma, small cell lung carcinoma, and colorectal carcinoma (Girard et al, 2000; Shivapurkar et al, 1999, 2001). Despite these regions showing a high incidence of deletion, none of the genes located in these regions was shown to fulfill the requirements for a TSG.

Several studies on chromosome 5 revealed deletion of the 5q21-22 region, the locus of the APC/MCC gene, involved in HNSCCs (Ah-See et al, 1994; Field et al, 1995; Mao et al, 1998). Nevertheless, mutation of the APC gene could not be displayed in SCC of the oral cavity or esophagus (Cooper et al, 1996; Shibagaki et al, 1994). In our study, the same locus showed a relatively high $\mathrm{LOH}$ frequency of $18 \%$ to
$27 \%$. On the other hand, we found much more frequent deletions in 5q31.3 (D5S1480, 54\%) and 5q13-14 (D5S1501, 45\%; D5S1462, 41\%). Both loci were defined as hot spots in various tumors, including nasopharyngeal carcinoma (Shao et al, 2001), oral carcinoma (Wolff et al, 1998), esophageal cancers (Ogasawara et al, 1996), and myeloid neoplasms (Horrigan et al, 2000). Our data, together with previous studies, suggest that some candidate TSGs in these regions are involved in the carcinogenesis of various cancers, including HNSCC.

Regarding the short arm of chromosome 8, the 8 p23 band was the most frequently deleted region in several solid tumors (Li et al, 2001; Pineau et al, 1999), including HNSCCs (Sunwoo et al, 1999; Wu et al, 1997). Our findings showed similar results, with a high incidence of $\mathrm{LOH}$ at the $8 \mathrm{p} 23$ location. Concerning $\mathrm{LOH}$ analysis on chromosome $8 \mathrm{q}$, the present study is the first report of the $8 q 13$ and 8q24 loci with high LOH frequency in HNSCCs. In other solid tumors, the 8 q24 loci in hepatocellular carcinoma and lung cancer (Girard et al, 2000; Li et al, 2001) and the 8q12-13 region in prostate cancer (Perinchery et al, 1999) were found to be commonly deleted. Conversely, the chromosomal region of 8 q24 was also found to be amplified in various malignancies, including hepatocellular carcinoma (Wang et al, 2001), prostate cancer (El Gedaily et al, 2001), and endometrial carcinoma (Suehiro et al, 2000). Most of the amplified chromosomal regions were detected by the comparative genomic hybridization technique, which shows loss or gain of DNA copy in an area rather than a specific locus. However, microsatellite analysis determines deletion in a specific locus. Thus, the comparison of these data obtained by two different methods should be done with caution.

The chromosome 9p23-24 region showed the second highest frequency of deletion in this study. Comparative genomic hybridization analysis on chromosome 9 also defined 9p23 and 9p24 loci as the most highly deleted regions for 73 different types of tumor entities (Knuutila et al, 1999). Field et al (1995) found the highest LOH frequency on 9p of HNSCC in accord with our results, although they focused on the 9p21 locus, in which at least four TSGs $(p 15, p 16, p 19$, and $M T A P)$ are located. We infer that an unknown TSG closely related to HNSCC resides on 9p24 rather than on 9p21. It is notable that at least 5 (25\%) of 20 tumors exhibited total loss of the short arm of chromosome 9 in our results (Fig. 3). In the $9 q$ arm, frequent $\mathrm{LOH}$ at the D9S930 (9q31.3) and D9S158 (9q34.2) markers in our study are consistent with previous studies in HNSCC (Ah-See et al, 1994; Field et al, 1995).

In the current study, frequent LOH was detected at a microsatellite marker D10S1221 in the 10q21 region. Comparative genomic hybridization analysis on chromosome 10 revealed $10 q 21$ as a hot spot locus with a high lymph node metastasis in HNSCC (Bockmuhl et al, 2000). Recently the ANX7 gene in the 10q21 locus was proposed as a TSG in prostate cancer (Srivastava et al, 2001). 
Regarding LOH analysis of chromosome 11, nasopharyngeal carcinomas of the Chinese population were reported to display frequent deletion of the 11q21-24 region (Harn et al, 2002; Hui et al, 1996). Our study revealed the 11q21 (D11S2000) and 11q22.3 (D11S2002) bands with $41 \%$ and $32 \%$ of $\mathrm{LOH}$, respectively. A microsatellite marker, ATA34E08 at the 11 14 location, showed high LOH. Similar results were shown in HNSCC, although the microsatellite markers used were different from ours (Bockmuhl et al, 1996).

Multiple minimal deleted regions including $13 q 14$ and 13q33-34 were determined for 13q in HNSCC (Gupta et al, 1999; Maestro et al, 1996). Previously we demonstrated the ING1 gene as a TSG at a hot spot of $\mathrm{LOH}$ in the 13q33-34 region (Gunduz et al, 2000). Concerning the $13 q 14$ region, at least two candidate TSGs other than $R B$, which have been proposed as oncosuppressors in diverse tumor types, were suggested in HNSCC (Maestro et al, 1996; Ogawara et al, 1998). In the current study, all markers on 13q showed an $\mathrm{LOH}$ frequency more than $40 \%$. Moreover, 4 of 20 tumors exhibited loss of all informative markers on 13q. All but one marker on chromosome 15 displayed a similar level of LOH frequency, whereas four samples demonstrated allelic loss of all markers, which made it difficult to define a minimal deleted region.

$\mathrm{LOH}$ analysis of $14 \mathrm{q}$ in HNSCC, except nasopharyngeal carcinoma, was poorly defined, and the 14q13-21 and 14q31-32 loci seemed to be frequently deleted (Califano et al, 1996; Nawroz et al, 1994). In our study, in addition to these regions, significant loss was found at the $14 q 11$ region. However, no TSG has been defined on chromosome 14 so far.

Deletion of the chromosome $17 \mathrm{p} 13$ region, which harbors a well-known TSG, p53, was shown in the transition from the preinvasive to the invasive lesion in various tumor types, including HNSCC (Boyle et al, 1993). Our results also confirmed the region proximal to the p53 gene (D17S1353) at 17p13 as the hottest spot, although no other significant deletion was found in other areas of chromosome 17.

Our microsatellite analysis on $19 q$ revealed the $19 q 12$ locus as a hot spot, which seemed to be selectively deleted in HNSCC (Field et al, 1995). We could not find frequent LOH on chromosomes 1, 7, 16, 21, and 22 at microsatellite markers used in this study; however, we have previously demonstrated that a specific narrow region at $7 q 31$, including the ING3 gene, exhibited a significantly high frequency of $\mathrm{LOH}$ in HNSCC (Gunduz et al, 2002). In addition, sex chromosomes could not be evaluated, because most markers examined were not informative.

In conclusion, the present comprehensive $\mathrm{LOH}$ analysis of HNSCC revealed 5 novel loci at which candidate TSGs may reside, in addition to the previously reported 15 loci. We also showed many new microsatellite markers with frequent $\mathrm{LOH}$, which can be useful in narrowing down the minimally deleted regions by comparing with previously reported data.

\section{Materials and Methods}

\section{Tissue Samples}

Paired normal and tumor samples were obtained from 22 patients with primary HNSCCs at the Department of Otolaryngology, Okayama University Hospital, after acquisition of written informed consent from each patient. Localizations of tumors included oral cavity (nine cases), hypopharynx (four), larynx (four), oropharynx (three), and maxillary sinus (two). All tissues were frozen in liquid nitrogen immediately after surgery and stored at $-80^{\circ} \mathrm{C}$ until the extraction of DNA and RNA. Histologic studies were also performed at the Department of Pathology, and all tumors were confirmed as squamous cell carcinoma.

\section{DNA Extraction}

Genomic DNAs were isolated from frozen tissues by $\mathrm{SDS} /$ proteinase $\mathrm{K}$ treatment, phenol-chloroform extraction, and ethanol precipitation.

\section{Microsatellite Analysis}

A genome-wide screening was performed with 191 markers spaced an average of $10 \mathrm{~cm}$ apart (The Map Pairs Human Screening Set, version 8.0; ResGen, Invitrogen Japan K.K., Tokyo, Japan). PCR was performed in $20 \mu$ l of reaction mixture with $10 \mathrm{pmol}$ of each primer, $100 \mathrm{ng}$ of genomic DNA, $1 \times$ PCR buffer, $200 \mu \mathrm{M}$ of each deoxynucleotide triphosphate, and 0.5 $\mathrm{U}$ of Taq DNA polymerase (Takara, Kyoto, Japan). Initial denaturation at $94^{\circ} \mathrm{C}$ for 3 minutes was followed by 25 cycles of a denaturation step at $94^{\circ} \mathrm{C}$ for 30 seconds, an annealing step between $50^{\circ} \mathrm{C}$ and $60^{\circ} \mathrm{C}$ depending on each primer for 30 seconds, and an extension step at $72^{\circ} \mathrm{C}$ for 1 minute. A final extension step at $72^{\circ} \mathrm{C}$ for 7 minutes was added. After amplification, $2 \mu \mathrm{l}$ of the reaction mixture was mixed with $8 \mu \mathrm{l}$ of loading dye (95\% formamide, $20 \mathrm{~mm}$ EDTA, 0.05\% bromphenol blue, and $0.05 \%$ xylene cyanol), heat denatured, chilled on ice, and then electrophoresed through an $8 \%$ polyacrylamide gel containing $8 \mathrm{M}$ urea. The DNA bands were visualized by silver staining (Bassam et al, 1991). LOH was scored if one of the heterozygous alleles showed at least $50 \%$ reduced intensity in tumor DNA as compared with the corresponding normal DNA. In some cases, PCR with fluorescent dye-labeled primers were used to analyze $\mathrm{LOH}$ with $\mathrm{ABI}-3100$ capillary sequencer and the GeneScan software (Applied BioSystems/Hitachi, Tokyo, Japan).

\section{Acknowledgments}

We thank the surgeons in the Department of Otolaryngology of our medical school for providing fresh specimens.

\section{References}

Ah-See KW, Cooke TG, Pickford IR, Soutar D, and Balmain A (1994). An allelotype of squamous carcinoma of the head and 
neck using microsatellite markers. Cancer Res 54:16171621.

Bassam BJ, Caetano-Anolles G, and Gresshoff PM (1991). Fast and sensitive silver staining of DNA in polyacrylamide gels. Anal Biochem 196:80-83.

Bockmuhl U, Schmidt S, Petersen S, and Petersen I (2000). Deletion of chromosome 10q: A marker for metastasis of head-neck carcinomas? Laryngorhinootologie 79:81-85.

Bockmuhl U, Schwendel A, Dietel M, and Petersen I (1996). Distinct patterns of chromosomal alterations in high- and low-grade head and neck squamous cell carcinomas. Cancer Res 56:5325-5329.

Boyle JO, Hakim J, Koch W, van der Riet P, Hruban RH, Roa RA, Correo R, Eby YJ, Ruppert JM, and Sidransky D (1993). The incidence of p53 mutations increases with progression of head and neck cancer. Cancer Res 53:4477-4480.

Califano J, van der Riet P, Westra W, Nawroz H, Clayman G, Piantadosi S, Corio R, Lee D, Greenberg B, Koch W, and Sidransky D (1996). Genetic progression model for head and neck cancer: Implications for field cancerization. Cancer Res 56:2488-2492.

Cooper CA, Bubb VJ, Smithson N, Carter RL, Gledhill S, Lamb D, Wyllie AH, and Carey FA (1996). Loss of heterozygosity at 5q21 in non-small cell lung cancer: A frequent event but without evidence of apc mutation. J Pathol 180:33-37.

Dammann R, Li C, Yoon JH, Chin PL, Bates S, and Pfeifer GP (2000). Epigenetic inactivation of a RAS association domain family protein from the lung tumour suppressor locus 3p21.3. Nat Genet 25:315-319.

El Gedaily A, Bubendorf L, Willi N, Fu W, Richter J, Moch H, Mihatsch MJ, Sauter G, and Gasser TC (2001). Discovery of new DNA amplification loci in prostate cancer by comparative genomic hybridization. Prostate 46:184-190.

Field JK, Kiaris H, Risk JM, Tsiriyotis C, Adamson R, Zoumpourlis V, Rowley H, Taylor K, Whittaker J, Howard P, et al (1995). Allelotype of squamous cell carcinoma of the head and neck: Fractional allele loss correlates with survival. $\mathrm{Br} \mathrm{J}$ Cancer 72:1180-1188.

Girard L, Zochbauer-Muller S, Virmani AK, Gazdar AF, and Minna JD (2000). Genome-wide allelotyping of lung cancer identifies new regions of allelic loss, differences between small cell and nonsmall cell lung cancer, and loci clustering. Cancer Res 60:4894-4906.

Gunduz M, Ouchida M, Fukushima K, Hanafusa H, Etani T, Nishioka S, Nishizaki K, and Shimizu K (2000). Genomic structure of the human ING1 gene and tumor-specific mutations detected in head and neck squamous cell carcinomas. Cancer Res 60:3143-3146.

Gunduz M, Ouchida M, Fukushima K, Ito S, Jitsumori Y, Nakashima T, Nagai N, Nishizaki K, and Shimizu K (2002). Allelic loss and reduced expression of the ING3, a candidate tumor suppressor gene at $7 \mathrm{q} 31$, in human head and neck cancers. Oncogene 21:4462-4470.

Gupta VK, Schmidt AP, Pashia ME, Sunwoo JB, and Scholnick SB (1999). Multiple regions of deletion on chromosome arm $13 q$ in head-and-neck squamous-cell carcinoma. Int J Cancer 84:453-457.

Harn HJ, Fan HC, Chen CJ, Tsai NM, Yen CY, and Huang SC (2002). Microsatellite alteration at chromosome 11 in primary human nasopharyngeal carcinoma in Taiwan. Oral Oncol 38:23-29.
Horrigan SK, Arbieva ZH, Xie HY, Kravarusic J, Fulton NC, Naik H, Le TT, and Westbrook CA (2000). Delineation of a minimal interval and identification of 9 candidates for a tumor suppressor gene in malignant myeloid disorders on $5 q 31$. Blood 95:2372-2377.

Hu N, Roth MJ, Polymeropolous M, Tang ZZ, Emmert-Buck MR, Wang QH, Goldstein AM, Feng SS, Dawsey SM, Ding T, Zhuang ZP, Han XY, Ried T, Giffen C, and Taylor PR (2000). Identification of novel regions of allelic loss from a genomewide scan of esophageal squamous-cell carcinoma in a high-risk Chinese population. Genes Chromosom Cancer 27:217-228.

Hui AB, Lo KW, Leung SF, Choi PH, Fong Y, Lee JC, and Huang DP (1996). Loss of heterozygosity on the long arm of chromosome 11 in nasopharyngeal carcinoma. Cancer Res 56:3225-3229.

Kisielewski AE, Xiao GH, Liu SC, Klein-Szanto AJ, Novara M, Sina J, Bleicher K, Yeung RS, and Goodrow TL (1998). Analysis of the FHIT gene and its product in squamous cell carcinomas of the head and neck. Oncogene 17:83-91.

Knudson AG Jr (1971). Mutation and cancer: Statistical study of retinoblastoma. Proc Natl Acad Sci USA 68:820-823.

Knuutila S, Aalto Y, Autio K, Bjorkqvist AM, El-Rifai W, Hemmer S, Huhta T, Kettunen E, Kiuru-Kuhlefelt S, Larramendy ML, Lushnikova T, Monni O, Pere H, Tapper J, Tarkkanen M, Varis A, Wasenius VM, Wolf $M$, and Zhu $Y$ (1999). DNA copy number losses in human neoplasms. Am J Pathol 155:683-694.

Kohno T, Otsuka T, Takano H, Yamamoto T, Hamaguchi M, Terada M, and Yokota $\mathrm{J}$ (1995). Identification of a nove phospholipase $\mathrm{C}$ family gene at chromosome $2 \mathrm{q} 33$ that is homozygously deleted in human small cell lung carcinoma. Hum Mol Genet 4:667-674.

Latif F, Tory K, Gnarra J, Yao M, Duh F-M, Orcutt ML, Stackhouse T, Kuzmin I, Modi W, Geil L, Schmidt L, Zhou F, Li H, Wei MH, Chen F, Glenn G, Choyke P, Walther MM, Weng Y, Duan DR, Dean M, Glavac D, Richards FM, Crossey PA, Ferguson-Smith MA, Le Paslier D, Chumakov I, Cohen D, Chinault AC, Maher ER, Linehan WM, Zbar B, and Lerman MI (1993). Identification of the von Hippel-Lindau disease tumor suppressor gene. Science 260:1317-1320.

Li SP, Wang HY, Li JQ, Zhang CQ, Feng QS, Huang P, Yu XJ, Huang LX, Liang QW, and Zeng YX (2001). Genome-wide analyses on loss of heterozygosity in hepatocellular carcinoma in Southern China. J Hepatol 34:840-849.

Maestro R, Piccinin S, Doglioni C, Gasparotto D, Vukosavljevic T, Sulfaro S, Barzan L, and Boiocchi M (1996). Chromosome $13 q$ deletion mapping in head and neck squamous cell carcinomas: Identification of two distinct regions of preferential loss. Cancer Res 56:1146-1150.

Mao EJ, Schwartz SM, Daling JR, and Beckmann AM (1998). Loss of heterozygosity at 5q21-22 (adenomatous polyposis coli gene region) in oral squamous cell carcinoma is common and correlated with advanced disease. J Oral Pathol Med 27:297-302.

Nawroz H, van der Riet P, Hruban RH, Koch W, Ruppert JM, and Sidransky D (1994). Allelotype of head and neck squamous cell carcinoma. Cancer Res 54:1152-1155.

Ogasawara S, Tamura G, Maesawa C, Suzuki Y, Ishida K, Satoh N, Uesugi N, Saito K, and Satodate R (1996). Common deleted region on the long arm of chromosome 5 in esophageal carcinoma. Gastroenterology 110:52-57. 
Ogawara K, Miyakawa A, Shiba M, Uzawa K, Watanabe T, Wang XL, Sato T, Kubosawa H, Kondo $\mathrm{Y}$, and Tanzawa $\mathrm{H}$ (1998). Allelic loss of chromosome 13q14.3 in human oral cancer: Correlation with lymph node metastasis. Int $\mathrm{J}$ Cancer 79:312-317.

Oh JJ, West AR, Fishbein MC, and Slamon DJ (2002). A candidate tumor suppressor gene, $\mathrm{H} 37$, from the human lung cancer tumor suppressor locus 3p213. Cancer Res 62:32073213.

Otsuka T, Kohno T, Mori M, Noguchi M, Hirohashi S, and Yokota J (1996). Deletion mapping of chromosome 2 in human lung carcinoma. Genes Chromosom Cancer 16:113119.

Perinchery G, Bukurov N, Nakajima K, Chang J, Hooda M, Oh BR, and Dahiya R (1999). Loss of two new loci on chromosome 8 (8p23 and 8q12-13) in human prostate cancer. Int J Oncol 14:495-500.

Pershouse MA, El-Naggar AK, Hurr K, Lin H, Yung WK, and Steck PA (1997). Deletion mapping of chromosome 4 in head and neck squamous cell carcinoma. Oncogene 14:369-373.

Pfister DG, Ruchlin HS, and Elkin EB (1997). Economic considerations in the care of patients with head and neck malignancies. Curr Opin Oncol 9:241-246.

Pineau P, Nagai H, Prigent S, Wei Y, Gyapay G, Weissenbach $J$, Tiollais P, Buendia MA, and Dejean A (1999). Identification of three distinct regions of allelic deletions on the short arm of chromosome 8 in hepatocellular carcinoma. Oncogene 18: 3127-3134.

Ransom DT, Barnett TC, Bot J, de Boer B, Metcalf C, Davidson JA, and Turbett GR (1998). Loss of heterozygosity on chromosome 2q: Possibly a poor prognostic factor in head and neck cancer. Head Neck 20:404-410.

Reed AL, Califano J, Cairns P, Westra WH, Jones RM, Koch W, Ahrendt S, Eby Y, Sewell D, Nawroz H, Bartek J, and Sidransky D (1996). High frequency of p16 (CDKN2/MTS-1/ INK4A) inactivation in head and neck squamous cell carcinoma. Cancer Res 56:3630-3633.

Renan MJ (1993). How many mutations are required for tumorigenesis? Implications from human cancer data. Mol Carcinog 7:139-146.

Shao JY, Huang XM, Yu XJ, Huang LX, Wu QL, Xia JC, Wang HY, Feng QS, Ren ZF, Ernberg I, Hu LF, and Zeng YX (2001). Loss of heterozygosity and its correlation with clinical outcome and Epstein-Barr virus infection in nasopharyngeal carcinoma. Anticancer Res 21:3021-3029.

Shibagaki I, Shimada Y, Wagata T, Ikenaga M, Imamura M, and Ishizaki K (1994). Allelotype analysis of esophageal squamous cell carcinoma. Cancer Res 54:2996-3000.

Shivapurkar N, Maitra A, Milchgrub S, and Gazdar AF (2001). Deletions of chromosome 4 occur early during the pathogenesis of colorectal carcinoma. Hum Pathol 32:169-177.

Shivapurkar N, Wistuba II, Virmani AK, Maitra A, Milchgrub S, Minna JD, and Gazdar AF (1999). Multiple regions of chromosome 4 demonstrating allelic losses in breast carcinomas. Cancer Res 59:3576-3580.
Somers KD, Merrick MA, Lopez ME, Incognito LS, Schechter GL, and Casey G (1992). Frequent p53 mutations in head and neck cancer. Cancer Res 52:5997-6000.

Srivastava M, Bubendorf L, Srikantan V, Fossom L, Nolan L, Glasman M, Leighton X, Fehrle W, Pittaluga S, Raffeld M, Koivisto P, Willi N, Gasser TC, Kononen J, Sauter G, Kallioniemi OP, Srivastava S, and Pollard HB (2001). ANX7, a candidate tumor suppressor gene for prostate cancer. Proc Natl Acad Sci USA 98:4575-4580.

Suehiro Y, Umayahara K, Ogata H, Numa F, Yamashita Y, Oga A, Morioka H, Ito T, Kato H, and Sasaki K (2000). Genetic aberrations detected by comparative genomic hybridization predict outcome in patients with endometrioid carcinoma. Genes Chromosom Cancer 29:75-82.

Sunwoo JB, Sun PC, Gupta VK, Schmidt AP, El-Mofty S, and Scholnick SB (1999). Localization of a putative tumor suppressor gene in the sub-telomeric region of chromosome $8 p$. Oncogene 18:2651-2655.

Takita J, Yang HW, Chen YY, Hanada R, Yamamoto K, Teitz T, Kidd V, and Hayashi Y (2001). Allelic imbalance on chromosome $2 q$ and alterations of the caspase 8 gene in neuroblastoma. Oncogene 20:4424-4432.

Uno M, Otsuki T, Yata K, Fujii T, Sakaguchi H, Akisada T, Hiratsuka J, Imajo Y, and Harada T (2002). Participation of Fas-mediated apoptotic pathway in KB, a human head and neck squamous cell carcinoma cell line, after irradiation. Int $\mathrm{J}$ Oncol 20:617-622.

Wang G, Zhao Y, Liu X, Wang L, Wu C, Zhang W, Liu W, Zhang $\mathrm{P}$, Cong W, Zhu Y, Zhang L, Chen S, Wan D, Zhao X, Huang W, and Gu J (2001). Allelic loss and gain, but not genomic instability, as the major somatic mutation in primary hepatocellular carcinoma. Genes Chromosom Cancer 31: 221-227.

Wang XL, Uzawa K, Imai FL, and Tanzawa H (1999). Localization of a novel tumor suppressor gene associated with human oral cancer on chromosome $4 \mathrm{q} 25$. Oncogene 18: 823-825.

Weber RG, Scheer M, Born IA, Joos S, Cobbers JMJL, Hofele C, Reifenberger G, Zuller JE, and Lichter P (1998). Recurrent chromosomal imbalances detected in biopsy material from oral premalignant and malignant lesions by combined tissue microdissection, universal DNA amplification, and comparative genomic hybridization. Am J Pathol 153: 295-303.

Wolff E, Girod S, Liehr T, Vorderwulbecke U, Ries J, Steininger H, and Gebhart E (1998). Oral squamous cell carcinomas are characterized by a rather uniform pattern of genomic imbalances detected by comparative genomic hybridization. Oral Oncol 34:186-190

Wu CL, Roz L, Sloan P, Read AP, Holland S, Porter S, Scully C, Speight PM, and Thakker N (1997). Deletion mapping defines three discrete areas of allelic imbalance on chromosome arm $8 p$ in oral and oropharyngeal squamous cell carcinomas. Genes Chromosom Cancer 20:347-353. 